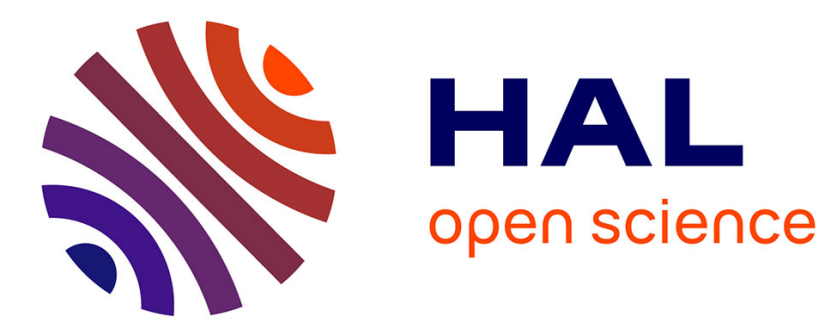

\title{
Knowledge, Hierarchy and incentives: Why human resource policy and trust matter
}

\author{
Nathalie Lazaric, Alain Raybaut
}

\section{To cite this version:}

Nathalie Lazaric, Alain Raybaut. Knowledge, Hierarchy and incentives: Why human resource policy and trust matter. International Journal of Technology and Globalisation, 2007, 3 (1), pp.8-23. hal00453292

\section{HAL Id: hal-00453292 \\ https://hal.science/hal-00453292}

Submitted on 4 Feb 2010

HAL is a multi-disciplinary open access archive for the deposit and dissemination of scientific research documents, whether they are published or not. The documents may come from teaching and research institutions in France or abroad, or from public or private research centers.
L'archive ouverte pluridisciplinaire HAL, est destinée au dépôt et à la diffusion de documents scientifiques de niveau recherche, publiés ou non, émanant des établissements d'enseignement et de recherche français ou étrangers, des laboratoires publics ou privés. 


\title{
Knowledge, hierarchy and incentives: why human resource policy and trust matter
}

\author{
Nathalie Lazaric* and Alain Raybaut \\ GREDEG-DEMOS, \\ CNRS/University of Nice Sophia Antipolis, \\ 250 rue A. Einstein 06560 Valbonne, France \\ E-mail: lazaric@idefi.cnrs.fr \\ E-mail: raybaut@idefi.cnrs.fr \\ ${ }^{*}$ Corresponding author
}

\begin{abstract}
This paper analyses the motivational dimension in the firm within different organisational set-ups characterised by their levels of hierarchical pressure and two types of bonus rules, a Gaussian and a non Gaussian distribution perceived as more risky by the employees. The model shows the importance of the rules for vertical trust building. In particular, trust increases with the perception of more safety concerning the bonus. However, the degree of risk of the bonus rule distribution is not always negatively correlated to the level of profit. The model also suggests that vertical trust may prevail even in a hierarchical structure.
\end{abstract}

Keywords: vertical trust; connectivity; effort convention; hierarchy; knowledge creation.

Reference to this paper should be made as follows: Lazaric, N. and Raybaut, A. (2007) 'Knowledge, hierarchy and incentives: why human resource policy and trust matter', Int. J. Technology and Globalisation, Vol. 3, No. 1, pp.8-23.

Biographical notes: Nathalie Lazaric is CNRS Research Fellow. These last years she has explored the dynamics of routines, processes of learning and knowledge creation in firms and networks and focused on the creation, change and dynamics of routines within firms. She also dedicated an important effort on the problems related to the definition of knowledge and its relations with economics. Actually, she is also involved in the forms of knowledge management, especially in relation with epistemic forms of organisation.

Alain Raybaut is CNRS Research Fellow. His research interests cover history of economic thought, business cycles theory and the economics of knowledge. In this topic, his main concern is to understand the dynamical properties of complex systems and networks characterised by social and cognitive interactions, with particular applications to organisations and electronic markets.

\section{Introduction}

The co-evolution of incentives and cognitive mechanisms is actually one of the most promising questions for the theory of the firm because "the fact that incentives are not taken into account is a drawback shared by all evolutionary of the firm" 
(Garrouste and Saussier, 2005). For this reason, knowledge should not simply be understood as a pure cognitive process but also as a locus in which the political dimension becomes critical (for some attempting formalisation see Dosi et al. (2003)). Groups, teams or communities of practice play an important part in the creation of knowledge and could be an appropriate organisational design for implementing specific incentives like rewards or bonus (Cohendet and Llerena, 2003). Knowledge creation by such 'horizontal communities' may require appropriate intervention for regulating their creativity (Miles and Snow, 1992; Miles et al., 1997; Foss, 2003). In an innovative context where knowledge has to be combined quickly, it may be difficult for traditional hierarchical structures to monitor novelty. Indeed, as noticed by Hodgson,

\begin{abstract}
"to some degree, the management roles of gendarme and educator may conflict with one another. The cultivation of a common corporate culture may require a degree of trust between employees and employer and between employees themselves. However, habits of trust may be undermined by the excessive use of the gendarme role and the presumption by management that employees are potentially opportunistic." (Jacoby, 1990 in Hodgson, 2004, p.411) ${ }^{1}$
\end{abstract}

This is the reason why the nature of organisational rules becomes crucial for the development of coercive or enabling hierarchical relations. Among these rules, the salary rules are the most delicate and sensitive ones (Livet and Reynaud, 1998; Reynaud, 1998, 2005). They are also highly controversial and challenging for the implementation of a suitable human resource policy inside the firm. It is thus important for a better understanding of the coupling of incentives and cognitive mechanisms to study here more deeply the role played by such rules in centralised or decentralised organisational set-up.

From this standpoint, the paper is organised in the following way. We first briefly discuss the literature relating the motivational context, particularly the rewards or bonus issue, with the importance of rules and trust in the evolutionary theory of the firm. Second, we model the dynamics of groups during knowledge creation in the presence of different bonus rules. Our main numerical findings on their impact on trust and performances of the firm are then presented, leading to some concluding remarks in the final section.

\title{
2 The motivational context of the firm: organisational rules and trust issues
}

As well known, the main goal of the firm is, according to the evolutionary conception, to build a set of specific capabilities, either technological or organisational ones. The motivational context in the evolutionary theory of the firm is far from being a commonplace or a very well-delimited research agenda (about these difficulties for introducing the social dimensions see Coriat and Dosi, 1998; Lazaric and Denis, 2005; Lazaric and Raybaut, 2005). In fact, this issue was initially present in the seminal book of Nelson and Winter (1982) via the truce argument, which introduces the social aspects of routines for explaining the stability of the organisation. Indeed, if routines are not stabilised or activated with permanent conflicts between organisational members, coordination cannot be achieved effectively. In a previous work, we have developed a framework depicting the importance of truce and conflicts with the ability of different organisational set-ups to cope with the political dimension for sustaining their performance (Lazaric and Raybaut, 2005). It is however necessary to go a step further in 
this perspective, with the analysis of the motivational dimension during knowledge creation. For this reason, three main issues, namely, the notion of 'effort convention', the bonus rules and vertical trust will particularly deserve our attention.

\subsection{The puzzle of the 'effort convention' or how to observe the worker's commitment}

As we may recall, the potential analytical interest offered by the combination of the industrial relations arguments with the daily functioning of the firm through its firm internal labour market à la Doeringer and Piore (1971) was notably suggested by Nelson and Winter (1982, p.110). Accordingly, as noticed by Leibenstein, this idea implies that "substantial areas of behavioural discretion" exist within organisations. The hierarchical structure could not control the daily routines of its members because they are able to exercise their discretionary power (Leibenstein, 1987). The relevance of this argument is clear: whatever the intention underlying an action taken in a particular circumstance, inertia may prevail because the firm's members may choose to resist the managerial dynamics and decide to maintain their organisational practices and their autonomy (Hannan and Freeman, 1984; Lazaric and Denis, 2005). In this perspective, Leibenstein's (1979) suggestion is to explore the "micro-micro theory of the firm" to have a better understanding of the social context in which the individuals modify their effort. According to him, this debate is general since,

"many organisations allow for conflict resolution through a hierarchical system (...). But despite a hierarchical power structure, informal degrees of influence may play a significant role." (Leibenstein, 1979, p.480)

This remark suggests taking into consideration the importance of organisational trust between organisational members who try to find a trade-off between their own interest and the organisational one (Simon, 1991). ${ }^{2}$ This compromise, called the 'effort convention', is a situation in which the individuals have a discretionary choice of their level of performance in quantity and in quality. This 'effort convention' between organisational members is described as a 'social habit' or "a routine that has an interpersonal component" (Leibenstein, 1982, p.93). In addition, trust is crucial for the coordination and performance in a context of knowledge creation in which employment contracts are incomplete. Thus, in Leibenstein's perspective, trust is a precondition of the "effort convention" (Leibenstein, 1975, 1987). Trust has two dimensions in his terminology: a vertical and a horizontal one. Without 'limited trust', a climate of suspicion between workers prevails, leading them to condemn any incentives measures implemented by the management. If mistrust is generated by the management, because of 'factionalism', the 'vertical trust' is difficult to implement and incentives policy will become a problematic issue. Trust issue is obtained with some precarious equilibrium between vertical and horizontal trust inside the firm (Leibenstein, 1987, see also Guennif and Mangolte (2002)). As we may recall, the puzzling issue of the maintenance of a certain level of effort between groups or teams has also been explored by Akerlof (1982). In the job called 'cash posting', the surplus concerning the productivity's workers $(+15 \%)$ could be explained by a social behaviour leading employees to anthropomorphise the organisation by considering this institution as a locus where gifts could be exchanged. Employees' gift (in the context a high labour productivity) will be considered in a long-term perspective and will push employers to give a certain level of fair wage to their 
employees. As well known, Akerlof's arguments explain why the employer may have an incentive to pay the employees more than the market clearing wage. This argument, however, does not clarify the heart of the motivation of the employees. Trust dimension needs to be explored for a better understanding of this issue in the internal labour market when employees and employers face strong uncertainties (Williamson, 1993). ${ }^{3}$

\subsection{A tentative human resource policy: the bonus rules}

Organisational rules as political compromises play a crucial role for maintaining the 'effort convention', even if rules are quite ambiguous by nature and contain many possible interpretations (March et al., 2000; Schulz, 2003; Reynaud, 2005). Their revision and suspension is a critical process that reinforces or reduces organisational trust and consequently the 'effort convention' in the organisation. The well-known description of the Japanese firm and its comparison with the American one illustrates quite well this process (Aoki, 1990; Coriat, 1991). Indeed, the evolution of career opportunities for the employees in the Japanese firm shows a diversity of implicit and explicit rules to cope with various internal or external shocks and to reallocate the share of productivity among the diverse categories of employees (Shimizu, 1999). ${ }^{4}$

The recent study of Reynaud (2005) dedicated to the introduction of a productivity bonus rule in the Paris Metro shows how this type of rules has partially biased the selection of task inside various teams in charge of the equipment maintenance. The teams face the following alternative: maximise labour productivity in the short run to receive the full bonus or, in a longer-term perspective, continue to do their job as usual with and an appropriate trade-off between usual services and corrective procedures. The bonus-based productivity of workers enters in contradiction with the traditional routines and leaves the opportunity for the workers to choose the easiest procedure. This example shows clearly the nature of operators' choices who tried, on the one hand, to benefit from the productivity bonus and on the other hand to preserve a fair way of doing their task. The importance of fairness inside industrial relations illustrates why 'vertical trust' - in the Leibenstein terminology - is important during the revision of the organisational rules between the organisational members.

The recent change of rules in the internal labour market of IBM France is in the same spirit (for an overview of IBM HRM policy, see Foulkes, 1980; Wood, 1996, 1999). Indeed, in 2002, IBM introduced the following new rule: Teams first agree on prior objectives and actually obtain a remuneration increasing with the degree of realisation of theses objectives, based on a ranking from 1 to 4 . The implementation of such ranking has produced the emergence of contentions and conflicts because the rule was judged too risky and too subjective with strong inequalities in the distribution of the bonus. According to trade unions, this conflicting state resulted in the instauration of mistrust between employees and employer accompanied by the end of regular wage increases. Thus, the implementation of new rules often shows the disruption of a prevailing state of truce with the emergence of permanent conflicts among the organisational members, impeding a smooth coordination inside the firm (Arrieux, 2004; Eymard-Duverney, 2005). ${ }^{5}$ 


\subsection{Vertical trust or how to reduce uncertainty inside the firm}

Indeed, Reynaud (1998) considers organisational trust as the back draw of the efficiency of salary schemes. In this context, trust is not a spontaneous process and may be grounded in collective practices, leading to learn implicit commitments inside the firm. Diverse rules may be present; for example a 'step-by-step' engagement between employers and employees could create some positive externalities, a learning that will be useful in the presence of strong uncertainties, causal ambiguities, contract incompleteness and tacit commitments (Lazaric and Lorenz, 1998). Moreover, the possibility that employer and employees may not share the same skills increases the risk of misunderstanding and fallacious judgements for each part (Demsetz, 1988; Connor and Prahalad, 1996). Indeed, during knowledge creation, when contract between employer and employees are incomplete, trust plays a crucial role. First, trust overpasses tasks ambiguities and misinterpretation; second, it reduces the potential gap of skills between employer and employees (Adler, 2001; Ferrin and Dirks, 2003; Szulzanski et al., 2004; Lazaric and Lorenz, 1998; Minkler, 1993). Consequently, trust creates a climate that makes easy creativity and innovation.

An important distinction made in the literature is between the micro and macro foundations of trust (Nooteboom, 2002). Micro foundations generally refer to individual issues like the perception of self-interest or bonds of friendship or love between the agents. Macro sources, we will focus on in this paper, include sanctions from an authority (be it the patriarch, the law or the hierarchy) attempting to canalise conflicts inside an organisation. They may also include internalised norms of proper conduct, which also serve to reduce uncertainty regarding an agent's likely behaviour (Arena et al., 2005). The sources of trust in an organisation may be macro in nature. For example, we may trust an organisation because of what we believe to be the case about its internal governance structure and how its incentives system sanctions employees' behaviour and encourages them to fulfil the requirements of their various functions and roles.

In the context of knowledge creation where uncertainty and causal ambiguity remains high - notably during transfer of knowledge - the motivation of organisational members and their potential 'absorptive capacity' turn into key elements (Szulzanski et al., 2004). Then, 'cognitive distance' is far to be neutral as it could increase or decrease the level of uncertainty and the effective absorptive capacity (Nooteboom, 2000). The achievement of a sufficient alignment of cognitive maps is also necessary to enable mutual understanding. Indeed, in order to achieve a specific task, the categories of thought of people that are interacting, must be aligned to a certain extent. The role of the organisation is therefore, on the one hand, to reduce cognitive distances between its members. On the other hand, the range of cognitive distances refers to the variety of knowledge and capacities of the organisation's members. It therefore plays an important positive role in the process of knowledge creation. Consequently, a certain trade-off must be reached, which means that the organisation must simultaneously reduce causal ambiguity and favour a certain cognitive variety. The network of cognitive interactions characterising the organisation is therefore the representation of this trade-off. The structure of this network is formally captured by its level of connectivity. This is the reason why creativity in each group relies on the achievement of a certain level of connectivity among them, in addition to trust, which maintains a high motivation for sustaining effort. 
On the basis of these three key points discussed above, we now propose a model of the dynamics of groups during knowledge creation in presence of different bonus rules. Indeed, we first assume that the process of vertical trust building in the firm depends on the perception of the rule by the groups. Second, we suppose that the level of cognitive interactions of each group (connectivity) coupled with vertical trust determines the capability of the group to create knowledge. Then, the model tries to illustrate from an analytical standpoint the various trade-offs workers encounter and to explain the puzzle of co-evolution of incentives and cognitive mechanisms.

\section{Knowledge, bonus rule and trust dynamics: a model}

Let us consider a firm organised around $n$ interacting different groups $i$. Define by $x_{i}(t)$ the level of activation of organisational practice of group $i$. This variable captures the intensity of commitment of the members of the group engaged in an organisational practice. We assume that the level of effort of each group, $e_{i}(t)$, depends positively on $x_{i}(t)$. Thus we have for $i=1, \ldots, n$.

$$
e_{i}(t)=\left\{x_{i}(t)\right\}^{\alpha}
$$

with $0<\alpha \leq 1$. The hierarchy tries to regulate the efforts exercised by the different groups by promoting an average effort norm $\bar{e}(t)=1 / n \sum_{i=1}^{n} e_{i}(t)$. Organisational rules concerning the bonus policy are introduced in order to encourage the energy mobilised in each group. We suppose that a bonus is given to a group when its effort is at least equal to the average norm. That is when $h_{i}(t) \geq 0$, where $h_{i}(t)=e_{i}(t)-\bar{e}(t)$. In that case, the group receives a bonus $\tilde{\gamma} h_{i}(t)$, where $\tilde{\gamma}$ is a random variable with strictly positive values. Indeed, uncertainty prevails in the amount of available pay supplement. In addition, as discussed above, these rules may be modified more or less frequently by the hierarchy.

We suppose that $\gamma$ follows a Weinbull distribution $W[a, b]$. This distribution, as is shaped below, ranges from a Gaussian distribution when $a$ is large to an exponential law when $a$ decreased (see Figure 1):

Figure 1 Modifications with $a$ of the $P D F$ of $W[a, b],(b=2)$

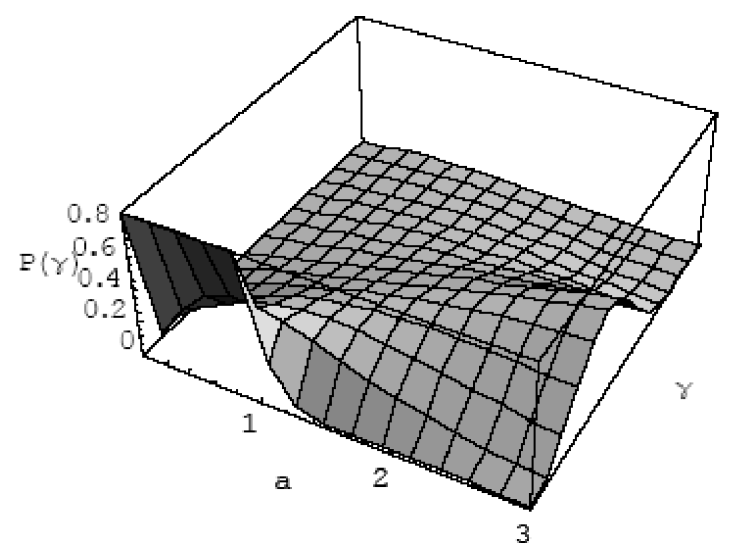


In this perspective, we focus on two polar types of rules, a quite risk-less rule and an unwarranted risk-bearing one. In the first case (GD), the distribution is Gaussian (large $a$ ). When they produce a sufficient level of effort, groups have the highest probabilities to receive to a certain extent an average bonus rate $\gamma^{6}$. This type of rule may favour risk adverse behaviours but is also favourable, as shown below, to the improvement of vertical trust. Conversely, in the second case (NGD), the distribution is non-Gaussian (small $a$ ) and is biased. Efficient groups have here the highest probabilities to receive a very small bonus rate $\gamma$ and a small probability to get a very large one. This type of rule encourages risk-oriented behaviours, but it may as well impede the development of vertical trust.

From this standpoint, let us define by $\tau_{i}(t)$ the level of vertical trust of group $i$ at time $t$. We suppose that

$$
\tau_{i}(t)=\phi+\left(\mu E\left(\tilde{\gamma} h_{i}(t)\right)-v S\left[\tilde{\gamma} h_{i}(t)\right]\right) z_{i}(t)
$$

where, $z_{i}(t)$ is an indicative variable such that

$$
z_{i}(t)=\left\{\begin{array}{l}
0 \text { if } e_{i}(t)<\bar{e}(t) \\
1 \text { if } e_{i}(t) \geq \bar{e}(t)
\end{array}, E\left[\tilde{\gamma} h_{i}(t)\right] \text { and } S\left[\tilde{\gamma} h_{i}(t)\right]\right.
$$

are the expected value and the standard deviation of the distribution $W[a, b]$ of the bonus rule, and $\mu>0 \mu>0$ and $v>0$ are two adjustment parameters. The mean of a Weinbull distribution $W[a, b]$ is equal to $b \Gamma[1+1 / a]$ and its standard deviation to $b \sqrt{\Gamma[1+2 / a]-\Gamma[1+1 / a]^{2}}$. We suppose that $\phi>0$ captures the collective dimension of trust building among groups. Besides, the process of trust building is improved when the expected value of the bonus distribution is high, while rules with important standard deviation play a depleting role.

Finally, the process of knowledge creation is localised and modelled in each group by a Poisson process with an arrival rate $\lambda_{i}(t)$, where for $i=1, \ldots, n$ :

$$
\lambda_{i}(t)=\frac{\tau_{i}(t) c_{i}(t)}{\sigma} .
$$

The first element $\tau_{i}(t)$ encapsulates the role played by trust in the process of knowledge creation. Accordingly, we suppose that a positive relation exists between trust and the propensity of group $i$ to create knowledge. High $\tau_{i}(t)$ favour knowledge creation, while small ones inhibit this process.

The second element, $c_{i}(t)$, refers to the role played by cognitive interactions between groups. The structure of interactions is determined endogenously as follows. Define for $i=1, \ldots, n, X_{i}(t)$ by $X_{i}(t)=x_{i}(t)+x_{j}(t) d_{i j}$, where, $d_{i j}$ is a distance between $i$ and $j$. We suppose that the gain of $i$ produced by the interaction with $j$ is $\left\{X_{i}(t)\right\}^{\eta}$, with $0<\eta \leq 1$. This captures the fact that the idiosyncratic practice of $i$ benefits from exchanges of experience with the other groups $j$ connected to $i$. We consider that $d_{i j}$ stands for some cognitive distance between the different kinds of knowledge owned by the agents. Thus, we assume that distance plays a positive role in the process of knowledge creation; but as discussed above this distance is also costly. Assume that this cost function is given by $\left\{X_{i}(t)\right\}^{\theta}$, where, $\theta>1$, then $i$ creates a link with $j$ if and only if 
$\left\{X_{i}(t)\right\}^{\eta}-\left\{X_{i}(t)\right\}^{\theta}>0$. Consequently, a critical distance $d_{i j}^{*}(t)$ exists such that the structure of connections of $i, i=1, \ldots, n$ to $j=1, \ldots, n$, with $i \neq j$ satisfies

$$
d_{i j}<d_{i j}^{*}(t)
$$

where

$$
d_{i j}^{*}(t)=\frac{(\eta / \theta)^{1 /(\theta-\eta)}-x_{i}(t)}{x_{j}(t)} .
$$

In the rest of the paper, we simply assume that $d_{i j}=|i-j|$.

Let, for $i \neq j, l_{i j}(t)=1$ if $i$ is connected to $j$ and $l_{i j}(t)=0$ otherwise. The connectivity of group $i, c_{i}(t)$, is defined as the average number of links of $i$ with $j \neq i, j=1, \ldots, n$. Thus, we have

$$
c_{i}(t)=\frac{\sum_{j \neq i} l_{i j}(t)}{n-1} .
$$

Finally, $\sigma>0$ is a parameter that encapsulates the influence of the organisational set-up on knowledge creation. This parameter is an indicator of the hierarchical pressure from classical hierarchies $(\sigma>1)$ to pure networking firms $(\sigma \leq 0)$. Consequently, in relation (3), we suppose that the higher $\sigma$, the smaller the expected value of knowledge creation in group $i, \lambda_{i}(t)$.

Production in the firm is the outcome of the total level of effort $E(t)=\sum_{i=1}^{n} e_{i}(t)$ resulting from the different groups. We have:

$$
Q(t)=B(t)\{E(t)\}^{\beta}
$$

The term $B(t)$ refers to a global learning mechanism that captures the accumulation of knowledge within the firm. We have $B(t)=1+\sum_{i=1}^{n} \lambda_{i}(t) e_{i}(t)$. Then, total profits are given by the profit function:

$$
\Pi(t)=p B(t)\{E(t)\}^{\beta}-w E(t)
$$

where, $0<\beta \leq 1 ; p$ refers to the exogenous market price of the production and $w$ is the wage rate, which captures the direct cost of labour. ${ }^{7}$

Finally, we suppose that the dynamics of the practices $x_{i}(t)$ is driven by the capacity of the group to create knowledge $\lambda_{i}(t) e_{i}(t)$, with $i=1, \ldots, n$. Hence, we consider the following system of $n$ coupled differential equations:

$$
\frac{\mathrm{d} x_{i}(t)}{\mathrm{d} t}=x_{i}(t)\left[\lambda_{i}(t) e_{i}(t)-\delta x_{i}(t)\right]
$$

where $\delta, 0<\delta<1$, refers to the exogenous obsolescence rate of the practices (see Figures 2a and 2b). 
Figure 2a (a) Type 1 connectivity $t=0$ and (b) type 1 connectivity $t=t_{\text {Max }}$

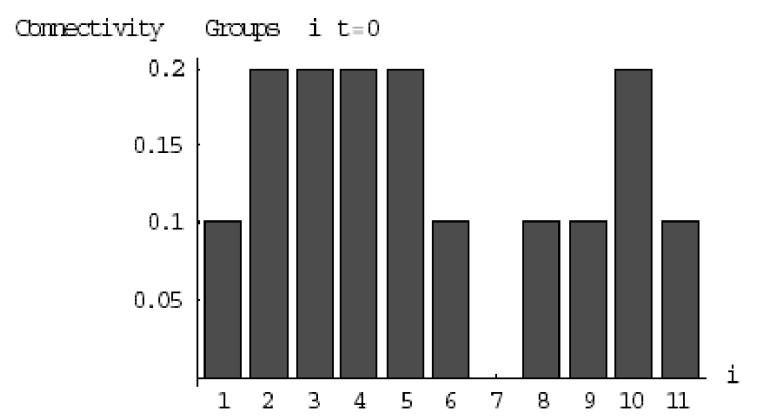

(a)

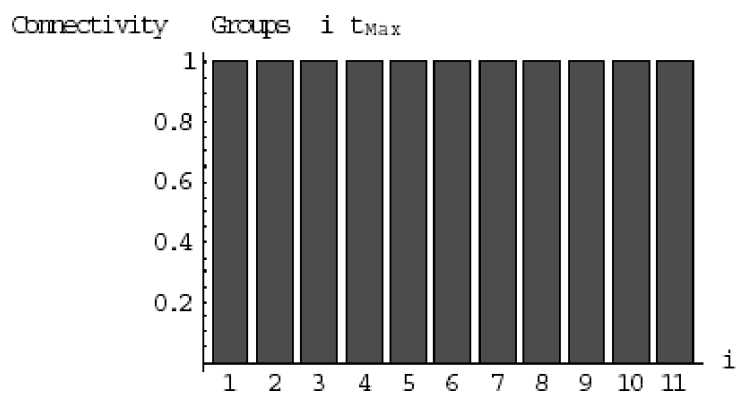

(b)

Figure 2b (a) Type 2 connectivity $t=0$ and (b) type 2 connectivity $t=t_{\text {Max }}$

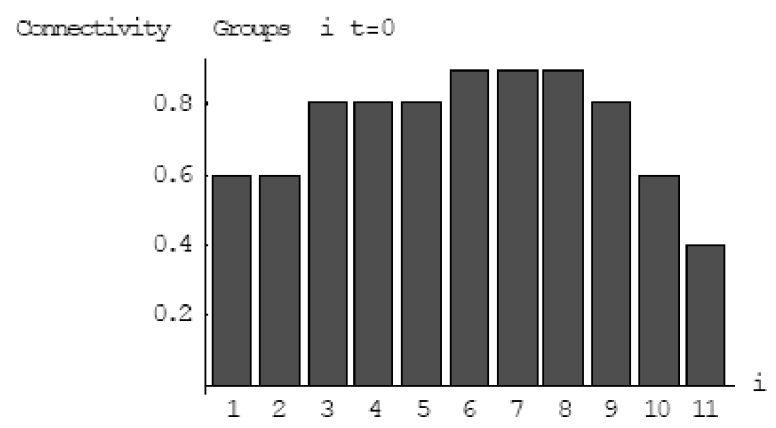

(a)

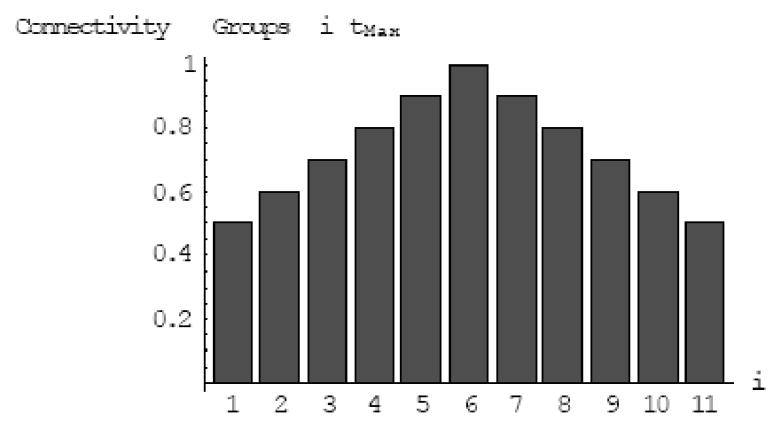

(b) 
In the rest of the paper, we conduct numerical simulations of this system to characterise the impact of the bonus rate rule on the dynamics of trust and profitability in different organisational set-ups.

Accordingly, we consider two polar cases for the bonus rule, a Gaussian distribution, where $a=2.5$ and a non-Gaussian one (exponential law), where $a=0.5$ (see Figure 1).

Variety in the organisational designs is a by-product of two factors, the set of the $n$ levels of connectivity $c_{i}(t)$ in each group and the hierarchical pressure $\sigma$. Concerning connectivity, starting with an initial random incomplete structure of links between groups, we consider two configurations. In the first one, the dynamics eventually produces a structure of complete graph, whereas it remains incomplete in the second case.

Then in the different cases, we compare the properties of the model when the pressure of the hierarchy is neutral for knowledge creation $(\sigma=1)$ and when it is higher $(\sigma=2)$, which tends to impede knowledge creation. The different configurations investigated are reported in Table 1.

Table 1 Configurations investigated in the simulations

\begin{tabular}{lllll}
\hline Connectivity & \multicolumn{2}{l}{ Gaussian bonus rule distribution } & $\begin{array}{l}\text { Non-Gaussian bonus rule } \\
\text { distribution } W(0.5,2)\end{array}$ \\
\hline Initial incomplete and & Low & Strong & Low & Strong \\
Final complete network & hierarchical & hierarchical & hierarchical & hierarchical \\
of interactions & pressure $\sigma=1$ & pressure $\sigma=2$ & pressure $\sigma=1$ & pressure $\sigma=2$ \\
Type 1 Connectivity & Case 1.1 & Case 1.2 & Case 1.3 & Case 1.4 \\
Initial and Final & Low & Strong & Low & Strong \\
incomplete network of & hierarchical & hierarchical & hierarchical & hierarchical \\
interactions & pressure $\sigma=1$ & pressure $\sigma=2$ & pressure $\sigma=1$ & pressure $\sigma=2$ \\
Type 2 Connectivity & Case 2.1 & Case 2.2 & Case 2.3 & Case 2.4 \\
\hline
\end{tabular}

The additional parameters of the model are specified in Table 2.

Table 2 Additional parameters

\begin{tabular}{ccccccccc}
\hline$b$ & $n$ & $\alpha$ & $\delta$ & $\beta$ & $w$ & $p$ & $\eta$ & $\theta$ \\
\hline 2 & 11 & $1,1 / 3$ & 0.1 & 0.75 & 1 & 10 & 0.3 & 2 \\
\hline
\end{tabular}

We reproduce in below an example of the results obtained in the different configurations summarised in Table 1.

\section{Results obtained with type 1 connectivity}

In this configuration, the network of interactions among groups is the following: We start with an incomplete graph in $t=0$, leading eventually to a complete graph in $t=t_{\text {Max }}$ (where $t_{\mathrm{Max}}=1 \times 10^{6}$ ). Thus, we have

For this structure of interactions, we compute a mean trust indicator $\sum_{i=1}^{n} \tau_{i}(t) / n$ and the level of total profits. The following results are obtained:

Figure 3 displays two regimes of trust, the first one associated with the Gaussian bonus rule distribution and the second with the non-Gaussian distribution. In addition, mean trust is always higher in the first regime. Thus, the nature of the bonus rule is 
crucial for vertical trust building. Indeed, groups are motivated by the incentive policy and their perception of risk of the bonus distribution. The Gaussian distribution is perceived as less risky and is therefore more likely to enable vertical trust building. On the contrary with the non-Gaussian rule, groups have to overcome an initial state of mistrust, leading eventually to a lower level of mean trust.

Figure 4 indicates first that the level of total profit is clearly negatively correlated with hierarchical pressure captured by the parameter $\sigma$. In this case (type 1 connectivity), connectivity is finally uniformly equal to unity for all groups, which reveals a complete graph structure of interactions. This network configuration is therefore higher profitable with a low level of hierarchy. This undoubtedly emphasises the importance of decentralised organisational set-up for sustaining knowledge creation and performances. Second, in Figure 4, it appears that, for a given level of $\sigma$, profits are ordered according to the nature of the bonus rule, which is captured by the role played by trust.

Figure 3 Mean trust with type 1 connectivity: Case 1.1 Mauve: Gaussian distribution with $\sigma=1$; Case 1.2 Green: Gaussian distribution with $\sigma=2$; Case 1.3 Blue: non-Gaussian distribution with $\sigma=1$ and Case 1.4 Red: non-Gaussian distribution with $\sigma=2$

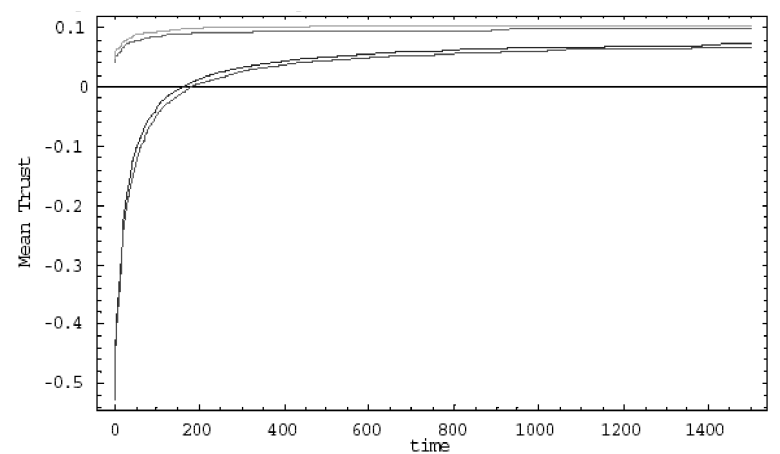

Figure 4 Total profits with type 1 connectivity: Case 1.1 Mauve: Gaussian distribution with $\sigma=1$; Case 1.2 Green: Gaussian distribution with $\sigma=2$; Case 1.3 Blue: non-Gaussian distribution with $\sigma=1$ and Case 1.4 Red: non-Gaussian distribution with $\sigma=2$

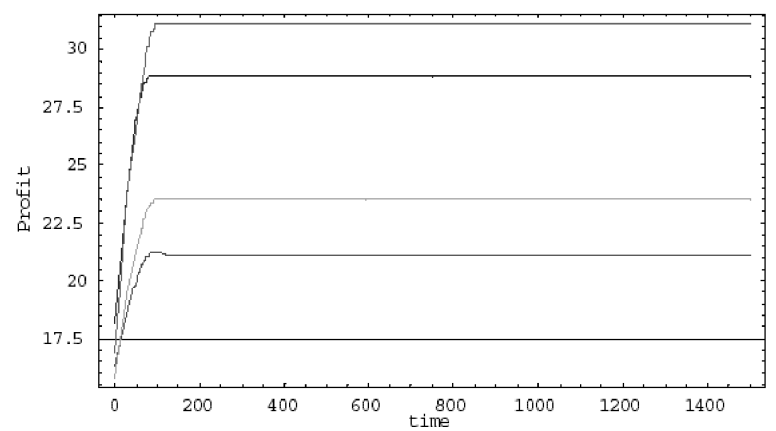

Results obtained with type 2 connectivity

In this example, the network of interactions among groups is the following: We start with an incomplete graph in $t=0$, leading eventually to an incomplete complete graph in $t=t_{\text {Max }}\left(\right.$ where $\left.t_{\text {Max }}=1 \times 10^{6}\right)$. Thus, we have: 
For this second structure of interactions, the following results are obtained:

In this second configuration where interactions are more dispersed (type 2 connectivity), the results are less contrasted. Indeed, as shown in Figure 5, we obtain the same kind of effect of the bonus rule on trust as above. But the two unambiguous regimes do not prevail and distinct sustained levels of trust are observed. In particular, the situation with important hierarchical pressure and Gaussian distribution (case 2.2) is trust dominant, which clearly indicates that a high level of hierarchy and vertical trust building are not always conflicting. Figure 6 shows that, on the whole, profitability is still negatively correlated with hierarchical pressure. However, this conclusion is more ambiguous for the intermediate configurations (cases 2.2 and 2.3). The Gaussian distribution with a high hierarchical pressure first dominates the non-Gaussian distribution with a lower hierarchical pressure: after a while the situation is lightly reversed. Thus in this case, the trade-off between some hierarchical pressure and the perception of risk remains quite indeterminate.

Figure 5 Mean trust with type 2 connectivity: Case 2.1 Mauve: Gaussian distribution with $\sigma=1$; Case 2.2 Green: Gaussian distribution with $\sigma=2$; Case 2.3 Blue: non-Gaussian distribution with $\sigma=1$; and Case 2.4 Red: non-Gaussian distribution with $\sigma=2$

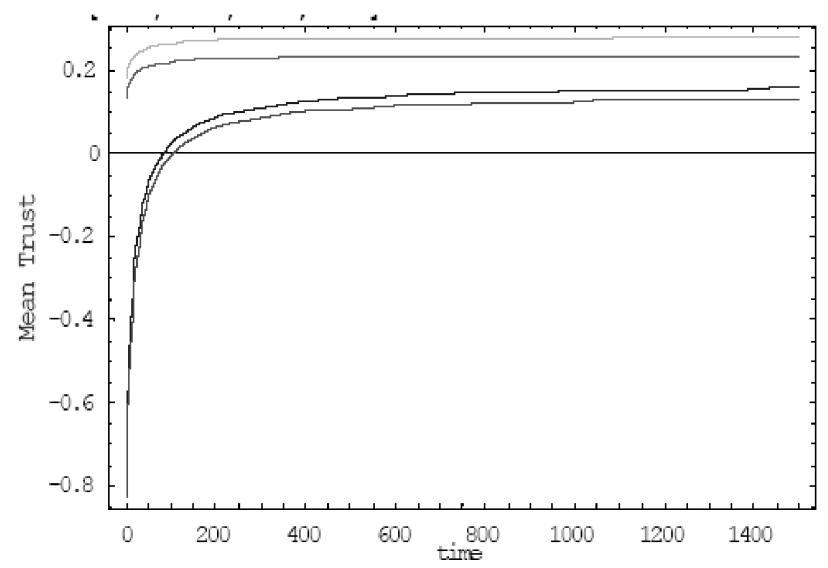

Figure 6 Total profits with type 2 connectivity: Case 2.1 Mauve: Gaussian distribution with $\sigma=1$; Case 2.2 Green: Gaussian distribution with $\sigma=2$; Case 2.3 Blue: non-Gaussian distribution with $\sigma=1$; and Case 2.4 Red: non-Gaussian distribution with $\sigma=2$

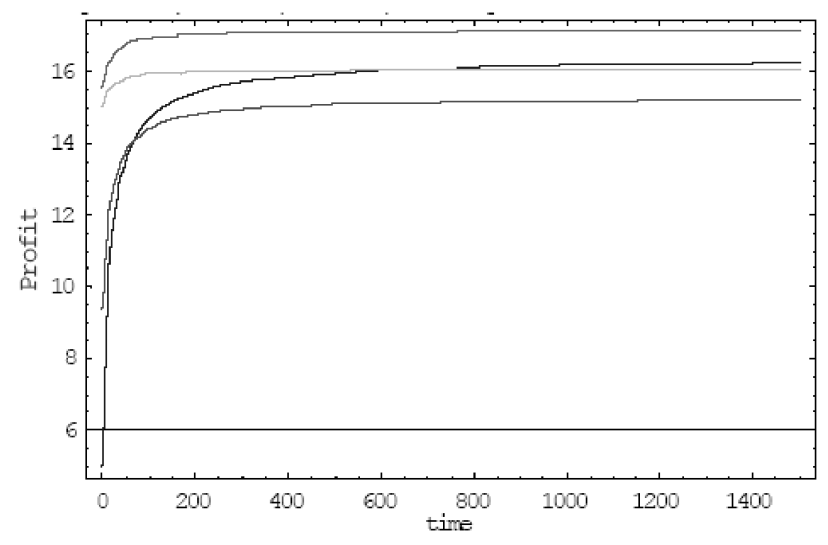




\section{Conclusion}

In this paper, we tried to investigate in a same analytical framework the co-evolution of cognitive and political mechanisms to discuss the motivational dimension in the firm. For this purpose, we refer to Leibenstein's concept of 'effort convention', which explains how groups and communities interact inside a hierarchical structure. Then, we discussed the importance of trust issues as a precondition for a suitable activation of the "effort convention'. Salary rules are crucial in this process notably for implementing some perception of risk concerning the bonus rule distribution and consequently for sustaining a certain state of motivation between organisation's members. In the numerical simulations of the model, we considered two types of bonus rules, a Gaussian and a non-Gaussian distribution perceived as more risky than the first one by the employees. These rules are compared within different organisational set-ups characterised by their levels of hierarchical pressure. Then, the model illustrates the importance of the rules for trust building. Indeed, the level of trust increases with the perception of more 'safety' concerning the distribution of the bonus. However, the degree of risk of the bonus rule distribution is not always negatively correlated to the level of profit and, in some peculiar cases, the 'risky rule' can be more profitable.

In addition, our results indicate that the structure of interaction between the diverse groups matters. Starting with an initial random incomplete structure of links between groups, we consider two configurations. In the first one, the dynamics eventually produces a structure of complete graph, whereas it remains incomplete in the second case. With the first type of connectivity, the network configuration is higher profitable with a low level of hierarchy, which emphasises the importance of decentralised organisational set-up for sustaining knowledge creation and performances. With the second type of connectivity, our results highlight a certain degree of indeterminacy between risk and hierarchical pressure. More generally, our model suggests that vertical trust may prevail even in a hierarchical structure. This quite unexpected result and the role of history in the process of vertical trust building should deserve more attention in a future research agenda.

\section{References}

Adler, P.S. (2001) 'Market hierarchy and trust: the knowledge Economy and the future of capitalism', Organization Science, Vol. 12, No. 2, March-April, pp.215-234.

Akerlof, G.A. (1982) 'Labor contracts as partial gift exchange', Quarterly Journal of Economics, Vol. 97, pp.543-569.

Aoki, M. (1990) 'Towards an economic model of the Japanese firm', Journal of Economic Literature, Vol. 28, pp.1-27.

Arena, R., Lazaric, N. and Lorenz, E. (2005) 'Trust, codification and epistemic communities: implementing an expert system in the French steel industry', forthcoming in Bachmann, R. and Zaheer, A. (Eds.): Handbook on Research on Trust, Edward Elgar, Londres, in press.

Arrieux, Y. (2004) Personal Business Commitment: IBM Changes the Rules of the Game-French Original Title: Notation Salariale: IBM Change les Règles du jeu-, Filigrane Press, 24/05/2004, Paris.

Cohendet, P. and Llerena, P. (2003) 'Routines and incentives: the role of communities in the firm', Industrial and Corporate Change, Vol. 12, No. 1, pp.271-297. 
Connor, K.R. and Prahalad, C.K. (1996) 'A resource-based theory of the firm', Organization Science, Vol. 7, pp.477-501.

Coriat, B. (1991) Penser à l'envers, Christian Bourgois (Eds.) Paris.

Coriat, B. and Dosi, G. (1998) 'Learning how to govern and learning how to solve problems: on the co-evolution of competences, conflicts and organizational routines', in Hagström, C.A. and Sövell, O. (Eds.): The Dynamic Firm: The Role of Technology, Strategy, Organization and Regions, Oxford University Press, Oxford, pp.103-133.

Demsetz, H. (1988) 'The theory of the firm revisited', Journal of Law, Economics, and Organization, Vol. 4, No. 1, Spring, pp.141-62; Reprinted in Williamson and Winter (1991).

Doeringer, P.B. and Piore, M.J. (1971) Internal Labor Markets and Manpower Analysis, M.E. Sharpe Inc., New York.

Dosi, G., Levinthal, D. and Marengo, L. (2003) 'Bridging contested terrain: linking incentives based and learning perspective on organizational evolution', Industrial and Corporate Change, Vol. 12, No. 1, pp.413-436.

Eymard-Duvernay, F. (2005) Defects of Cooperation and Unemployment: An Institutionnalist Theory - Original French Title 'Défauts de Coopération et Chômage: une Théorie Institutionnaliste-, CEE working paper no. 46, September.

Ferrin, D.L. and Dirks, K.T. (2003) 'The use of rewards to increase and decrease trust: mediating processes and differential effects', Organization Science, Vol. 14, No. 1, pp.18-31.

Foss, N. (2003) 'Selective intervention an internal hybrids: interpretating and learning from the rise and decline of the oticon spaghetti organization', Organization Science, Vol. 14, No. 3, May-June, pp.331-349.

Foulkes, F. (1980) Personnel Practices in Large Non-Union Companies, Prentice-Hall, Englewood Cliffs, NJ.

Garrouste, P. and Saussier, S. (2005) 'Looking for a theory of the firm: future challenges', JEBO, Vol. 58, No. 2, pp.178-199.

Guennif, S. and Mangolte, P.A. (2002) 'Analysis of organizational routines: proposal for an analytical framework based on Nelson and winter and Leibenstein', Working paper presented to the Conference, "Empirical Research on Routines in Business and Economics: Towards a Research Program”, Odense, 3-4 November.

Hannan, M. and Freeman, J. (1984) 'Structural inertia and organizational change', American Sociology Review, Vol. 49, No. 2, pp.149-164.

Hodgson, G.M. (2004) 'Opportunism is not the only reason why firms exist: why an explanatory emphasis on opportunism may mislead management strategy', Industrial and Corporate Change, Vol. 13, pp.401-418.

Jacoby, S.M. (1990) 'The new institutionalism: what can it learn form the old?', Industrial Relations, Vol. 29, pp.316-359.

Lazaric, N. and Denis, B. (2005) 'Routinisation and memorisation of tasks inside a workshop: an illustration through a case study', Industrial and Corporate Change, Vol. 14, No. 5, October, pp.873-896.

Lazaric, N. and Lorenz, E. (Eds.) (1998) Trust and Economic Learning, Edward Elgar, Londres.

Lazaric, N. and Raybaut, A. (2005) 'Knowledge, hierarchy and the selection of routines: an interpretative model with group interactions', Journal of Evolutionary Economic, Vol. 15, pp.393-421.

Leibenstein, H. (1975) 'Aspects of the X-efficiency theory of the firm', Bell Journal of Economics, Vol. 6, pp.580-606. 
Leibenstein, H. (1979) 'A branch of economics is missing: micro-micro theory', Journal of Economic Literature, Vol. XVII, June, pp.477-502.

Leibenstein, H. (1982) 'The prisoners' dilemma in the invisible hand: an analysis of intrafirm productivity', American Economic Review (Papers and Proceedings), Vol. 72, (1982) reprint in Putterman (1986).

Leibenstein, H. (1987) Inside the Firm: The Inefficiencies of Hierarchy, Harvard University Press, Cambridge.

Livet, P. and Reynaud, B. (1998) 'Organisational trust, learning and implicit commitment', in Lazaric, N. and Lorenz, E. (Eds.): Trust and Economic Learning, Edward Elgar, Londres, pp.266-284.

March, J., Schulz, M. and Zhou, X. (2000) The Dynamics of Rules. Change in Written Organizational Codes, Stanford University Press, Stanford.

Miles, R. and Snow, C.C. (1992) 'Causes of failure in network organizations', California Management Review, Vol. 34, No. 4, pp.53-72.

Miles, R., Snow, C.C., Mathews, J.A., Miles, G. and Coleman, J. (1997) 'Organizing in the knowledge age: anticipating the cellular form', Academy of Management Executive, Vol. 11, pp.7-20.

Minkler, A.P. (1993) The Problem with Dispersed Knowledge: Firms in Theory and Practice, Blackwell Publishing, Kyklos, Vol. 46, No. 4, pp.569-587.

Nelson, R. and Winter, S. (1982) An Evolutionary Theory of Economic Change, Belknap Press of Harvard University Press, Cambridge Mass.

Nooteboom, B. (2000) 'Learning by interaction: absorptive capacity, cognitive distance and governance', Journal of Management and Governance, Vol. 4, pp.69-92.

Nooteboom, B. (2002) Trust: Forms, Foundations, Functions, Failures and Figures, Edward Elgar, Cheltenham, UK.

Putterman, L. (1986) The Economic Nature of the Firm, a Reader, Cambridge University Press, pp.170-178.

Reynaud, B. (1998) 'Les conditions de la confiance, réflexions à partir du rapport salarial', Revue Economique, November, Vol. 49, No. 6, pp.1455-1472.

Reynaud, B. (2005) 'The void at the heart of rules: routines in the context of rule-following', Industrial and Corporate Change, Vol. 14, No. 5, October, pp.847-871.

Schulz, M. (2003) 'Impermanent institutionalization: the duration of dependence of organizational rule changes', Industrial and Corporate Change, Vol. 12, No. 5, pp.1077-1098.

Shimizu, K. (1999) Le Toyotisme, Edition La découverte Paris.

Simon, H. (1991) 'Organization and markets', Journal of Economic Perspectives, Vol. 5, pp.25-44.

Szulzanski, G., Cappetta, R. and Jensen, J.R. (2004) 'When and how trustworthiness matters: knowledge transfer and the moderating effect of causal ambiguity', Organization Science, Vol. 15, September-October, pp.600-613.

Williamson, O.E. (1993) 'Calculativeness, trust, and economic organization', Journal of Law and Economics, Vol. 36, No. 1, pp.453-486.

Williamson, O.E. and Winter, S.G. (Eds.) (1991) The Nature of the Firm: Origins, Evolution, and Development, Oxford University Press, Oxford and New York.

Wood, S. (1996) 'High commitment management and payment systems', Journal of Management Studies, Vol. 33, No. 1, pp.53-77.

Wood, S. (1999) 'Getting the measure of the transformed high-performance organisation', British Journal of Industrial Relations, Vol. 37, pp.391-417. 


\section{Notes}

${ }^{1}$ As Jacoby reports

"as industrial studies have repeatedly shown, the presumption of innate opportunism is fatal to trust ... It leads to a proliferation of control structures - supervision, rules, and deferred rewards - intended to inhibit opportunism. These create resentment and mistrust among employees, who correctly perceive the controls as expressions of their employer's distrust." (Hodgson, 2004; Jacoby, 1990, p.334)

${ }^{2}$ In the Simonian framework, the individuals in the organisation must accept the targets of the organisation and must identify psychologically with these targets (Simon, 1991).

${ }^{3}$ As well known, in the case considered by Akerlof the world is predictable by an exchange of gift. This situation has been depicted by Williamson with the notion of calculative trust where cooperation between farmers follows a predictable and regular way (Williamson, 1993).

${ }^{4}$ In Toyota some implicit rules were implemented for sharing the surplus among employees and for decreasing the unitary cost of production. The archetypical rule was the following:

- involvement of employees for constant and permanent improvement of quality and reductions of costs aim at reducing the unitary cost

- increasing of labour productivity

- $\quad$ increasing of global productivity and wages' increasing for employees (Shimizu, 1999).

During the middle of the 1990s, the hiring of temporary workers for facing the lack of manpower and financial markets' crisis led to revise salary rules and to reconsider the so-called 'horizontal coordination' due to an increasing complexity at intermediate levels (Shimizu, 1999). To sum up, Toyota story shows how rules are historical dependent and why new rules could emerge for sustaining new hierarchical relations inside the firm.

${ }^{5}$ For a longer discussion see Arrieux (2004) and Eymard-Duverney (2005).

${ }^{6}$ Assuming that the standard deviation of the distribution is not too large.

${ }^{7} \mathrm{We}$ thus implicitly suppose that the total productivity bonus is paid on the part of profits non-distributed to the shareholders. 